\title{
Died of wounds: a mortality review
}

\author{
Damian Douglas Keene, ${ }^{1}$ JG Penn-Barwell, ${ }^{2}$ PR Wood, ${ }^{1,3} \mathrm{~N} \mathrm{Hunt}^{4}{ }^{4} \mathrm{R}$ Delaney, ${ }^{5}$ \\ J Clasper, ${ }^{6}$ RJ Russell, ${ }^{7}$ PF Mahoney ${ }^{1,6}$
}

${ }^{1}$ Academic Department of Military Anaesthesia and Critical Care, Royal Centre for Defence Medicine, Birmingham, UK

${ }^{2}$ Institute of Naval Medicine, Gosport, UK

${ }^{3}$ Department of Anaesthesia, Queen Elizabeth Hospital, Birmingham, UK

${ }^{4}$ Forensic Pathology Services Wantage, Oxon, UK

${ }^{5}$ South West Group Practice, Bristol, UK

${ }^{6}$ Centre for Blast Injury Studies, Imperial College, London, UK

${ }^{7}$ Academic Department of Military Emergency Medicine, Royal Centre for Defence Medicine, Birmingham, UK

\section{Correspondence to} Maj Damian Douglas Keene, Academic Department of Military Anaesthesia and Critical Care, Institute of Research and Development, Birmingham Research Park, Vincent Drive, Birmingham B15 2SQ, UK

Damian.keene@me.com

Received 18 June 2015 Revised 5 September 2015 Accepted 21 September 2015 Published Online First 14 October 2015

\section{ABSTRACT}

Objectives Combat casualty care is a complex system involving multiple clinicians, medical interventions and casualty transfers. Improving the performance of this system requires examination of potential weaknesses. This study reviewed the cause and timing of death of casualties deemed to have died from their injuries after arriving at a medical treatment facility during the recent conflicts in Iraq and Afghanistan, in order to identify potential areas for improving outcomes.

Methods This was a retrospective review of all casualties who reached medical treatment facilities alive, but subsequently died from injuries sustained during combat operations in Afghanistan and Iraq. It included all deaths from start to completion of combat operations. The UK military joint theatre trauma registry was used to identify cases, and further data were collected from clinical notes, postmortem records and coroner's reports.

Results There were 71 combat-related fatalities who survived to a medical treatment facility; 17 (24\%) in Iraq and $54(76 \%)$ in Afghanistan. Thirty eight (54\%) died within the first $24 \mathrm{~h}$. Thirty-three $(47 \%)$ casualties died from isolated head injuries, a further $13(18 \%)$ had unsurvivable head injuries but not in isolation. Haemorrhage following severe lower limb trauma, often in conjunction with abdominal and pelvic injuries, was the cause of a further $15(21 \%)$ deaths.

Conclusions Severe head injury was the most common cause of death. Irrespective of available medical treatment, none of this group had salvageable injuries. Future emphasis should be placed in preventative strategies to protect the head against battlefield trauma.

\section{INTRODUCTION}

The invasion of Iraq in 2003 and the subsequent widening of operations in Afghanistan have resulted in a level of British Military casualties not seen since the conflict in Korea with 632 recorded deaths during the two conflicts. ${ }^{12}$

While the high level of medical activity has driven medical innovation, the route of casualty evacuation has remained relatively constant with casualties transferred to a medical treatment facility (MTF) by helicopter, stabilised for transfer back to the UK by a specialist critical care team approximately $24 \mathrm{~h}$ after injury ${ }^{3}$ and further acute care delivered in UK at the Royal Centre for Defence Medicine (RCDM), based within the University Hospitals Birmingham NHS Foundation Trust (UHBFT).

During these conflicts, the UK Defence Medical Services (DMS) implemented a healthcare governance programme aimed at improving the performance of the combat casualty care system, ${ }^{4}$ which has driven many advances at all stages of casualty

\section{Key messages}

- The majority of fatalities that occurred after casualties reached medical care died from unsurvivable head injuries caused by the initial insult at the time of injury.

- Most casualties (54\%) died within $24 \mathrm{~h}$ of injury.

- Further research should be directed at understanding how to improve protection to prevent or reduce head injury.

management. Physician-led care has been implemented during helicopter evacuation projecting forward the ability to initiate haemostatic resuscitation and deliver anaesthesia. ${ }^{5}$ MTF treatment has evolved with the further development of the concept of damage control resuscitation (DCR), consisting of rapid surgical control of bleeding with concurrent targeted haemostatic resuscitation. ${ }^{6-8}$ Alongside these changes, a greater emphasis has been placed on the importance of human factors and predeployment training, ensuring clinical currency among deploying personnel. ${ }^{9}$ Globally, this has resulted in significant improvements in survival of UK military casualties. ${ }^{10}$

In order to further improve survival beyond the high level seen at the end of military operations in Afghanistan in 2014, it is important to examine the group of severely injured patients who, though showing signs of life when they reach hospital, subsequently die as a result of their injuries. This group of patients are classified as those who have 'Died of Wounds' (DoW) (Table 1).

The aim of this study is to examine the DoW cohort of casualties to identify potential strategies for improving outcomes for those seriously injured on the battlefield. The primary objective is to characterise the mechanism and anatomic distribution of injuries seen in DoW casualties. The secondary objective is to examine the temporal patterns of fatality in the DoW cohort of casualties.

\section{METHODS}

This review was based on data from the Joint Theatre Trauma Registry (JTTR), the Mortality Peer Review Panel (MPRP) and the reports from the Forensic Pathologist and Coroner's court.

The JTTR is an electronic database of prospectively gathered information on casualties killed or injured during military service. Data are collected by trained trauma nurse coordinators (TNCs) working throughout the casualty chain. They were
To cite: Keene DD, Penn-

J $R$ Army Med Corps

2016;162:355-360. 
Table 1 Classifications of fatalities used in this study ${ }^{12}$

\begin{tabular}{ll}
\hline Died of Wounds (DoW) & $\begin{array}{l}\text { Personnel who die as a result of injuries inflicted by } \\
\text { hostile action after reaching a UK or coalition ally } \\
\text { Medical Treatment Facility (MTF) }\end{array}$ \\
$\begin{array}{l}\text { Died Non-Enemy } \\
\text { Action (DNEA) }\end{array}$ & $\begin{array}{l}\text { Personnel who die as a result of injuries caused by } \\
\text { non-hostile activity after reaching a UK or coalition ally } \\
\text { MTF }\end{array}$ \\
Killed in Action (KIA) & $\begin{array}{l}\text { Personnel killed instantly or before reaching a UK or } \\
\text { coalition ally MTF. Includes personnel arriving with } \\
\text { cardiopulmonary resuscitation in progress who do not } \\
\text { have any return of spontaneous circulation at the MTF } \\
\text { Personnel killed instantly or before reaching a MTF as } \\
\text { a result of non-hostile activity }\end{array}$ \\
\hline
\end{tabular}

present in deployed MTFs in Iraq and Afghanistan, at RCDM and attended British military postmortems. All fatalities and traumatically injured casualties that trigger a 'trauma alert' on presentation to a deployed MTF or casualties who subsequently require repatriation to the $\mathrm{UK}$ as a result of their injuries are included. The database is managed by the Clinical Information and Exploitation Team and administered by UK Defence Statistics. ${ }^{11}$ The MPRP is the process by which all postmortems on combat casualties are attended by a member of the Academic Department of Military Emergency Medicine and all cases reviewed by a group of military medical academics and other clinical and technical experts. ${ }^{12}$ The Forensic Pathologist with responsibility for postmortems of military fatalities and coroner from the relevant jurisdiction provided information on specific cases.

The JTTR was searched for all DoW cases from the start of operations in Iraq on 20 March 2003 until the end of combat operations in Afghanistan on 26 October 2014. Cases are classified as being Killed in Action (KIA), DoW, killed or died as a result of non-enemy action according to the definitions in Table 1.

Injury severity for each casualty was quantified using the New Injury Severity Score (NISS), which grades injuries from 1 to 75 with 75 being regarded as injuries incompatible with life. ${ }^{13}$ Individual injuries are classified using the military version of the Abbreviated Injury Scale (AIS), which divides injuries into eight anatomic regions with each injury graded from 1 to 6 with 1 being minor, and 5 or 6 classed as 'severe'. ${ }^{14}$ If any region scores 6, the casualty is automatically assigned a NISS of 75 . The NISS is calculated by summing the squares of the top three injury scores irrespective of body region. This is subtly different to Injury Severity Scoring (ISS) classically used in civilian practice were the squares of the top three regions are summed. ${ }^{15}$ This can lead to an underestimation of mortality in military casualties where there are multiple severe injuries in one anatomical region. For example, a casualty with bilateral lower limb amputations (AIS 5) and less severe injuries to other regions (AIS 4) would have an ISS score of $5^{2}+4^{2}+4^{2}=57$, whereas the NISS score would be higher ' $52+5^{2}+4^{2}=66$ '. ${ }^{16}$

Time of injury, arrival at hospital and death were obtained from JTTR and the postmortem records. Survival time was recorded in hours (if survival $<24 \mathrm{~h}$ ) or days (if survival $>24 \mathrm{~h}$ ). Cause of death was obtained from the death certificate, discussion with the forensic pathologist and from the information collected from the postmortems by the TNCs. When the cause of injury was recorded as 'blast injuries caused by explosion', more specific information on the key injuries was sought from the forensic pathologist postmortem report. When these were not available, a review of the RCDM/UHB hospital notes and injury data from JTTR were used to ascertain the most likely cause of death.

\section{RESULTS}

There were 2985 British military casualties in Iraq and Afghanistan during the study period by JTTR entries for UK casualties, of which $71(2.4 \%)$ died of wounds after having reached a MTF. The median prehospital transfer time from injury to arrival at the MTF was $51 \mathrm{~min}$ (IQR, 36-75). In addition to the 71 casualties, who DoW, 12 people died of non-enemy action. Overall, 54/71 DoW (76\%) were injured in Afghanistan and $17(24 \%)$ in Iraq. The median age was 23 years (range, 18-42), and 70 (98\%) were male.

The mechanism of injury was predominantly from explosive weapons rather than gunshot wounds (GSWs) with a ratio of $2: 1$, similar to overall wounding patterns from modern conflicts (Table 2). ${ }^{10}$ The median NISS of the 71 DoW casualties was 75 (IQR, 75-75); the survival timelines are shown in Figures 1 and 2 and analysis of interval after wounding for those who died within 30 days does not confirm a bimodal or trimodal distribution (Figure 3 ). ${ }^{17}$

\section{Location of DoW deaths}

In total, 48/71 (68\%) casualties died in the deployed MTF with $21(30 \%)$ dying in critical care units in the UK; there were no deaths during transfer to the UK. Two patients (2.8\%) died after discharge from hospital in the UK, both had a NISS of 75 and died several months after injury due to respiratory complications.

\section{Anatomical distribution of Injuries}

Within the DoW cohort, more than half had injuries to more than one body region with the overall distribution of injured body regions shown in Table 3.

\section{Head injury}

Of the 71 DoW casualties, 44 (62\%) had severe head injuries (39 AIS 6 and five AIS 5). The primary mechanism of injury was by explosion $(27,61 \%)$, with 13 having penetrating blast fragmentation injury, the remaining 17 (39\%) were GSWs. Thirty one of the 44 head injured casualties (71\%) had no other severely injured body regions (AIS 5 or 6). Overall, 42/44 patients were reviewed by the MPRP, and none were considered to be preventable deaths, irrespective of any additional deployed resources or change in clinician mix, such as deployment of a neurosurgeon.

\begin{tabular}{|c|c|c|c|}
\hline Mechanism & $\begin{array}{l}\text { Iraq } \\
n=17\end{array}$ & $\begin{array}{l}\text { Afghanistan } \\
\mathrm{n}=54\end{array}$ & $\begin{array}{l}\text { Total } \\
\mathrm{n}=71\end{array}$ \\
\hline GSW & 10 & 13 & $23(32 \%)$ \\
\hline Explosive & 7 & 41 & $48(68 \%)$ \\
\hline \multicolumn{4}{|c|}{ Time of death* } \\
\hline$<24 \mathrm{~h}$ & 13 & 25 & $38(54 \%)$ \\
\hline $1-30$ days & 4 & 23 & $27(38 \%)$ \\
\hline$>30$ days & 0 & 4 & $4(6 \%)$ \\
\hline
\end{tabular}




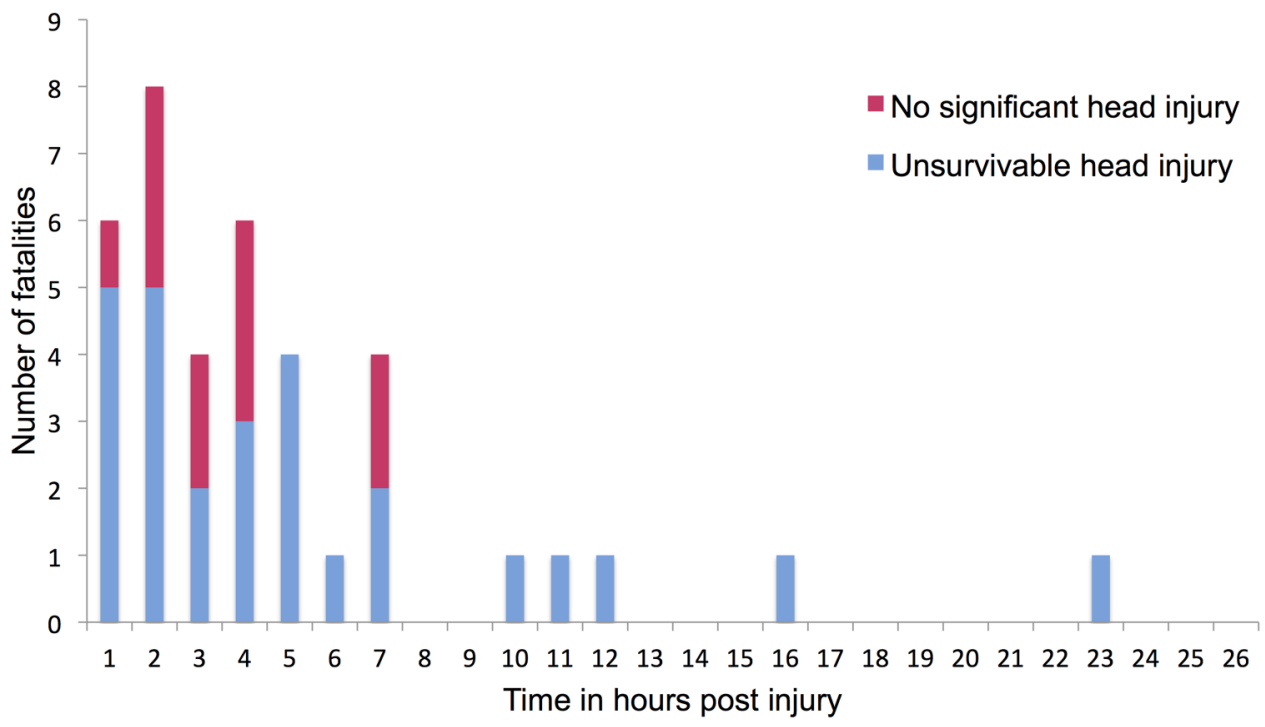

Figure 1 Time to death in hours post injury for deaths within $24 \mathrm{~h}$.

Of the 44, $26(59 \%)$ died within the first $24 \mathrm{~h}$, and $16(36 \%)$ survived for over $24 \mathrm{~h}$ with the data insufficient to determine survival in hours in two $(5 \%)$ patients. The survival times of head injured deaths within $24 \mathrm{~h}$ and between $24 \mathrm{~h}$ and 30 days can be seen in Figures 1 and 2 .

Two casualties died after more than 7 days, one due to pulmonary embolism secondary to pelvic venous thrombosis and the other of aspiration pneumonia as a complication of head injury.

\section{Lower limb injuries}

The next most common injury pattern was severe lower limb trauma which occurred in 17 (24\%) of the 71 casualties, and all were a result of explosive weapons; of these, two had unsurvivable head injuries and are included in the head injury results and are not discussed further here. Of the remaining 15 patients (all AIS =5), 13 had additional significant abdominal injuries of at least AIS 4 (nine AIS=4, four AIS=5); the median NISS was 57 (range, 50-75). This population represents severe lower extremity injuries, commonly high traumatic amputations, with associated severe pelvic/peritoneal trauma (Figure 4). Overall 8/ $15(53 \%)$ died within $7 \mathrm{~h}$ of injury, and seven (47\%) survived for at least 1 week.

The median survival of the seven casualties who survived for at least 7 days was 22 days (range, 7-557); of these, six died of multiorgan failure (MOF) and one died of acute respiratory distress syndrome (ARDS). Two casualties had isolated lower limb injuries, one of whom who died after $2 \mathrm{~h}$ was deemed to have been potentially salvageable by the MPRP if there had been improved haemorrhage control.

\section{Neck}

Six casualties had severe neck injuries (two AIS 6, four AIS 5); all had NISS scores of 75-the four who had severe injuries to the head (AIS $=6$ ) have been discussed above. The remaining two casualties had severe penetrating neck injuries (AIS 6) due to fragments from explosive weapons. Both had carotid artery injury resulting in severe haemorrhage, one with an associated watershed infarct. The survival times were 1 and 3 days. Mortality from neck wounds has been extensively described in previous work. ${ }^{18}$

Face

Four casualties had severe facial injuries (AIS 5). Three had nonsurvivable head injuries and have been discussed. One casualty's highest recorded AIS was to the face (AIS 5), implying that this injury was his primary cause of death. This casualty sustained multiple GSWs, including chest, abdomen and lower limbs (All AIS 4, ISS 57), and died after 24 days. No postmortem information was available.
Figure 2 Time to death in days for casualties dying after $24 \mathrm{~h}$ but within 30 days.

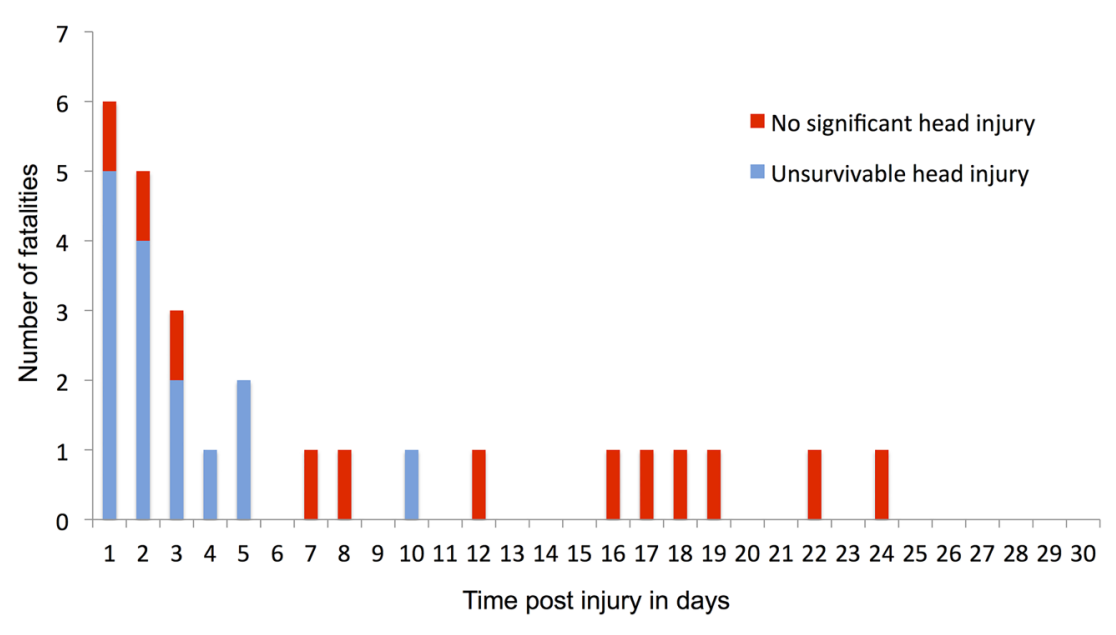

Keene DD, et al. J R Army Med Corps 2016;162:355-360. doi:10.1136/jramc-2015-000490 


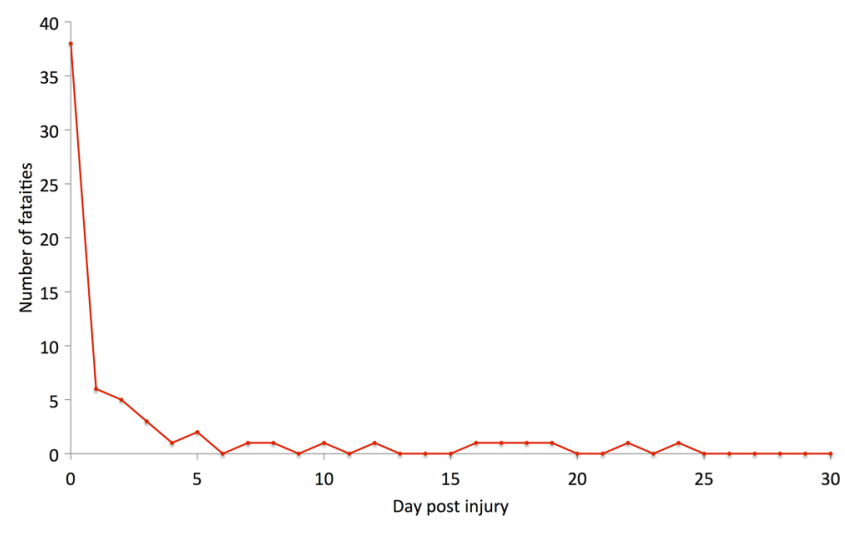

Figure 3 Distribution of death for all those within 30 days of injury.

\section{Chest}

Five casualties had severe chest injuries (one AIS $=6$, four AIS =5). Three had associated severe head injury and are not discussed further, and of the remaining two casualties, one sustained severe penetrating chest trauma (AIS 6) and abdominal injuries (AIS 5) as a result of explosion and died after 2 days as a result of ARDS. The other sustained a GSW to the chest and abdomen (AIS 5) and died after $3 \mathrm{~h}$.

\section{Abdominal injuries}

Six casualties sustained severe injuries to the abdomen (AIS 5), four had associated severe lower limb injury and two had a severe chest injury and all have been discussed.

\section{Spine}

Three casualties had severe spinal injuries (two AIS $=6$, one AIS =5), one with an associated severe head injury. One had chest injuries from a GSW (AIS 4) and died after $2 \mathrm{~h}$ from uncontrollable haemorrhage, while the other had a significant high cord contusion and died after 2 days.

\section{Injury severity outliers}

Five casualties had no individual AIS scores of 5 or 6 , three from explosions causing injuries to the abdomen and lower limbs. One died 8 days after injury from meningitis, and although this casualty had the lowest injury severity (NISS 29), his death was deemed unavoidable by the MPRP. One casualty died from MOF 16 days after injury-his NISS was 41 and the MPRP judged that his injuries were unsalvageable. The remaining casualty died after $1 \mathrm{~h}$ (NISS 41), and his injuries were deemed to be possibly salvageable by the MPRP.

The remaining two casualties in this group died after sustaining GSWs; one had a chest injury and died $6 \mathrm{~h}$ post injury and the second casualty died at 18 days due to multiple GSWs

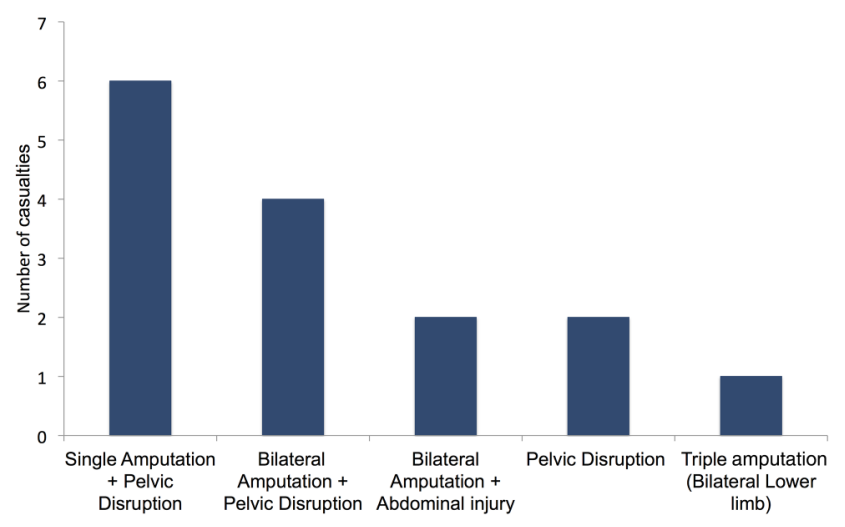

Figure 4 Injury patterns for casualties with significant lower limb injuries.

resulting in abdominal (AIS 4) and lower limb injuries (AIS 4). No further postmortem data were available.

\section{Cause of death}

A cause of death was assigned to 68/71 (96\%) casualties on the basis of data from the JTTR, postmortems, clinical notes and Coroner's report; 33 deaths (47\%) were a direct result of head injury alone, haemorrhage was implicated in $22(31 \%)$, nine resulted from MOF (13\%), two from ARDS (3\%), one from PE $(1 \%)$ and one due to meningitis $(1 \%)$. Three $(4 \%)$ had no postmortem data available.

\section{DISCUSSION}

These findings demonstrate that the majority of deaths in this cohort are as a result of unsurvivable head injury, however, a number of casualties died following severe injuries to the lower limbs/pelvis/abdomen and two may have survived with improved haemorrhage control. This is the first study examining UK DoW casualties during recent combat operations in Iraq and Afghanistan, although there have been several studies examining this cohort in US casualties.

In 2009 Martin et $a l^{19}$ published a retrospective study describing US casualties who died after arrival at a single combat support hospital in Iraq. They found that head injury was the most common cause of death (45\%); the majority died within $1 \mathrm{~h}$ of admission (78\%), and their mean ISS was 38 .

Two retrospective studies from Eastridge's research group found similar findings regarding head injury and haemorrhage. The 2011 study examined the cause of death and survivability of US DoW casualties between 2001 and $2009^{20}$ and described head injury as the most common cause of death in those (83\%) with non-survivable injury, where as haemorrhage was the most common cause of death in those with potentially survivable

Table 3 Distribution of injured anatomic regions in the 71 Died of Wounds (DoW) casualties

\begin{tabular}{llllllrrr}
\hline AIS (Highest scoring injury per region) & Head & Face & Neck & Thorax & Abdomen & Spine & Upper limb & Lower limb \\
\hline 1 & 3 & 9 & 0 & 2 & 2 & 1 & 5 \\
2 & 1 & 9 & 4 & 6 & 7 & 10 & 16 & 2 \\
3 & 0 & 0 & 0 & 4 & 2 & 0 & 3 & 5 \\
4 & 3 & 0 & 2 & 11 & 13 & 5 & 4 & 7 \\
5 & 5 & 4 & 4 & 4 & 7 & 1 & 2 \\
6 & 39 & 0 & 2 & 1 & 0 & 1 & 0 \\
\hline
\end{tabular}


injury. The follow-on study in 2012 considered all US personnel who died as a result of combat operations between 2001 and 2011 -overall $87 \%$ of all fatalities died prior to arrival at an MTF. As with the DoW cohort, the most common cause of death in those deemed to have unsurvivable injuries was traumatic brain injury. ${ }^{21}$

A large retrospective US study looked at casualties who died between 2002 and 2011 with the aim of examining the effect of the implementation of DCR in the DoW cohort. They found that the proportion of head injury deaths in the DoW group rose from $57 \%$ to $73 \%$ after widespread introduction of DCR techniques. There was a similar rise in mean ISS of the DoW cohort from 22.5 to 26.7 after DCR implementation. ${ }^{22}$ The improved survival rates seen in UK casualties over the same period are similarly believed to be due in part to improved techniques of treating massive haemorrhage rather than treating severe head injury. ${ }^{10}$

The US papers report similar findings to this study. Most casualties dying after reaching MTFs do so due to unsurvivable head injuries, but there are still a small number of potentially salvageable casualties who die from complications of massive haemorrhage following severe lower extremity trauma. The outcome from penetrating head injury in admissions to UK deployed field hospitals between 2003 and 2011 was a mortality rate of $41.3 \%$ with better survival from blast fragmentation than GSW, ${ }^{23}$ but the study included all civilian and military personnel and did not include closed head injury.

The implications of all these results are that there are two potential strategies to improve survival in the DoW cohort. The first is to further improve haemorrhage control and resuscitation. Eastridge $e t a^{21}$ found that non-compressible truncal or junctional injury was the most common cause of death in US DoW casualties who died from massive haemorrhage. Previous research looking at injury patterns in UK casualties has shown that the bleeding in casualties with this injury pattern was not amenable to tourniquet control. ${ }^{24} \mathrm{~A}$ promising area of development is in the use of novel endovascular techniques to control haemorrhage earlier in truncal or junctional injury. ${ }^{25}$

The second strategy addresses the largest group in the DoW cohort, those with massive head injuries. Improvements in medical treatment in this group are unlikely to improve outcome due to irreversible damage to the central nervous system sustained at the time of the incident. Previous work has demonstrated that changes to personal protective equipment (such as the introduction of improved eye protection) can reduce penetrating injury and that computer-based modelling can aid the development of protective equipment. ${ }^{26} 27$

Further research should be directed at understanding how to improve personal protection from penetrating and closed head injury, ${ }^{28}$ but will require further collaboration with both material scientists and industry.

No obvious distribution in timing of death was seen in these results. Specifically, the findings of this study do not support the concept of the trimodal distribution of the timing of death, which has been widely misattributed to the 1984 paper by Bellamy. ${ }^{17}$ That study's main assertion is not that there is a temporal, trimodal distribution of deaths, but that there was a trinity of causality of death over time. He predicted that head injury would be the greatest cause of death and this would wane over the first 7 days; haemorrhage would be the next greatest cause of death, but would be replaced by sepsis and organ failure (Figure 5). This is consistent with the findings of this study.

This study is not without limitations. The methodology is reliant on the accuracy of data in the JTTR, and it is recognised that there were considerable refinements and improvements in

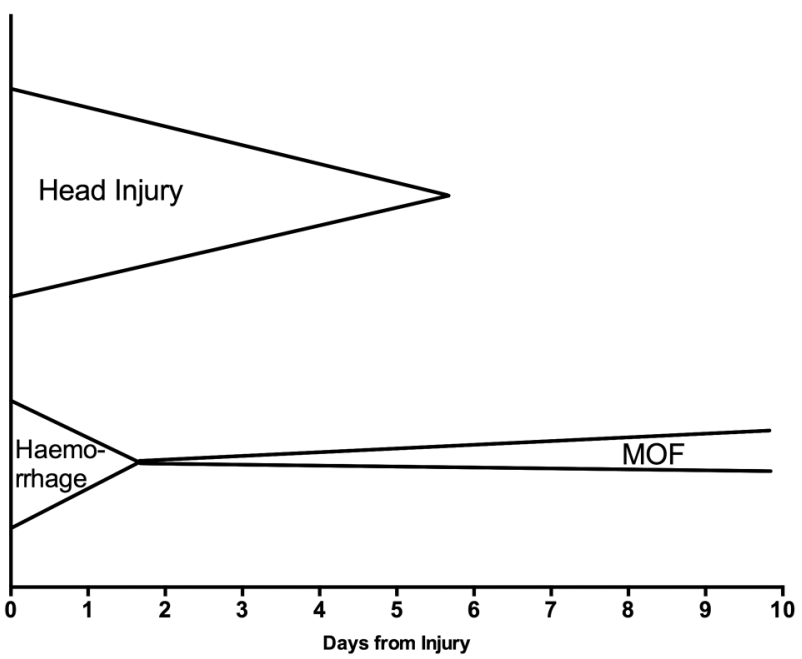

Figure 5 'Trinity of causality' adapted from Belamy et al. ${ }^{17}$ MOF, multiorgan failure.

the registry over the first 3 years of this study meaning that early data may be less reliable. Similarly, AIS coding is subjective and may introduce inaccuracies. The cause of death was difficult to confirm in a number of patients due to the complexity of injury; this required review of documentation from several sources in order to obtain the most likely cause of death making some findings reliant on individual interpretation.

We did not examine casualties who were KIA in this study, and further work is needed to assess time of death after injury in all fatalities; although given the nature of combat operations, this information may be challenging to accurately collect. Furthermore, it may prove useful to examine the differences in injuries and treatment between the unexpected survivors and the DoW cohort to target future research and refine clinical protocols. Finally, the cohort itself is small, so, conclusions must be made cautiously. Despite these limitations, the authors believe that this work increases understanding of the most serious injured casualties and indicates possible areas for further improvements in survival.

\section{CONCLUSION}

In fatally injured casualties, who are still alive when reaching a MTF, the biggest single cause of death is isolated head injury, and only a small number of casualties are dying with potentially treatable haemorrhage. Future research should be directed at improving battlefield head protection and further refinement of the clinical treatment of massive haemorrhage.

Contributors DDK: lead author and data collector. JGP-B: second author, significant input into content and layout of submission. PRW initial data collection, reviewed content of paper. NH and RD: provided significant input during data collection. JC: assisted in data analysis and redraft of paper. RJR: advice regarding data capture, input into paper content and layout. PFM: guidance on initial concept and approach to data capture, content reviewer.

Competing interests None declared.

Patient consent The review was carried out under RCDM Audit CAA-04491-12. Permission to access pathologist reports was obtained from the relevant Home Office Forensic Pathologists and Coroners.

Provenance and peer review Not commissioned; externally peer reviewed.

\section{REFERENCES}

1 Op Herrick casualty and fatality tables to 28 February 2015. https://www.gov.uk/ government/uploads/system/uploads/attachment_data/file/413527/20150310_ 
British_casualties_in_Afghanistan_70ct01_to_28Feb15.pdf (accessed 10 Jun 2015).

2 British fatalities Operations in Iraq. https://www.gov.uk/government/ fields-of-operation/iraq (accessed Jul 2015).

3 Turner S, Ruth M, Tipping R. Critical care Air Support teams and deployed intensive care. J R Army Med Corps 2009;155:122-74.

4 Hodgetts TJ, Davies S, Russell R, et al. Benchmarking the UK military deployed trauma system. J R Army Med Corps 2007;153:237-8.

5 Kehoe A, Jones A, Marcus $S$, et al. Current controversies in military pre-hospital critical care. J R Army Med Corps 2011;157:S305-9.

6 Holcomb JB. Damage control resuscitation. J Trauma 2007;62:S36-7.

7 Doughty HA, Woolley T, Thomas GO. Massive transfusion. J R Army Med Corps 2011;157:S277-83.

8 Midwinter MJ. Damage control surgery in the era of damage control resuscitation. J R Army Med Corps 2009;155:323-6.

9 Mercer S, Whittle CL, Mahoney PF. Lessons from the battlefield: human factors in defence anaesthesia. BJA 2010;105:9-20.

10 Penn-Barwell JG, Roberts SA, Midwinter MJ, et al. Improved survival in UK combat casualties from Iraq and Afghanistan: 2003-2012. J Trauma Acute Care Surg 2015;78:1014-20

11 Smith J, Hodgetts T, Mahoney $P$, et al. Trauma governance in the UK defence medical services. J R Army Med Corps 2007;153:239-42.

12 Russell R, Hunt N, Delaney R. The Mortality Peer Review Panel: a report on the deaths on operations of UK Service personnel 2002-2013. J R Army Med Corps 2014;160:150-4

13 Osler T, Baker SP, Long W. A modification of the injury severity score that both improves accuracy and simplifies scoring. J Trauma 1997;43:922-5.

14 Association for the Advancement of Automotive Medicine. Abbreviated Injury Scale 2005. Barrington, Illinois, 2005.

15 Baker SP, O'Neill B, Haddon W, et al. The injury severity score: a method for describing patients with multiple injuries and evaluating emergency care. J Trauma 1974:14:187-96
16 Russell RJ, Hodgetts TJ, McLeod J, et al. The role of trauma scoring in developing trauma clinical governance in the Defence Medical Services. Philos Trans $R$ Soc Lond B Biol Sci 2011;366:171-91.

17 Bellamy RF. The causes of death in conventional land warfare: implications for combat casualty care research. Mil Med 1984;149:55-62.

18 Breeze J, Allanson-Bailey LS, Hunt NC, et al. Mortality and morbidity from combat neck injury. J Trauma Acute Care Surg 2012;72:969-74.

19 Martin M, Oh J, Currier $\mathrm{H}$, et al. An analysis of in-hospital deaths at a modern combat support hospital. J Trauma 2009;66:S51-60.

20 Eastridge BJ, Hardin M, Cantrell J, et al. Died of wounds on the battlefield: causation and implications for improving combat casualty care. J Trauma 2011;71:S4-8.

21 Eastridge BJ, Mabry RL, Seguin P, et al. Death on the battlefield (2001-2011): implications for the future of combat casualty care. J Trauma Acute Care Surg 2012;73:S431-7.

22 Langan NR, Eckert M, Martin MJ. Changing patterns of in-hospital deaths following implementation of damage control resuscitation practices in US forward military treatment facilities. JAMA surgery 2014;149:904-12.

23 Smith JE, Kehoe A, Harrisson SE, et al. Outcome of penetrating intracranial injuries in a military setting. Injury 2014;45:874-8.

24 Morrison JJ, Ross JD, Rasmussen TE, et al. Resuscitative endovascular balloon occlusion of the aorta: a gap analysis of severely injured UK combat casualties. Shock 2014:41:388-93.

25 Morrison JJ, Ross JD, Houston R, et al. Use of resuscitative endovascular balloon occlusion of the aorta in a highly lethal model of noncompressible torso hemorrhage. Shock 2014;41:130-7.

26 Breeze J, Allanson-Bailey LS, Hunt NC, et al. Surface wound mapping of battlefield occulo-facial injury. Injury 2012;43:1856-60.

27 Breeze J, ,Allanson-Bailey LC, Hepper AE, et al. Novel method for comparing coverage by future methods of ballistic facial protection. Br J Oral Maxillofac Surg 2015;53:3-7.

28 Breeze J, Baxter D, Carr D, et al. Defining combat helmet coverage for protection against explosively propelled fragments. J R Army Med Corps 2015;161:9-13. 